\title{
ANALISIS PENGENDALIAN KUALITAS UNTUK MENGENDALIKAN TINGKAT CACAT PRODUK CLOSET DUDUK PADA PT. XYZ
}

\author{
Mega Inayati Rif'ah ${ }^{1)}$, Eric Sandi Yudha ${ }^{2}$ \\ ${ }^{1,2)}$ Fakultas Teknologi Industri, Jurusan Teknik Industri, Institut Sains \& Teknologi AKPRIND \\ Jl. Kalisahak No. 28, Kompleks Balapan, Yogyakarta, 55222 \\ Email: megainaya@akprind.ac.id, ericyudha2808@yahoo.com
}

\begin{abstract}
ABSTRAK
PT. XYZ adalah perusahaan yang memproduksi Sanitary Wares yang mengutamakan kualitas produk yang dihasilkannya. PT. XYZ menyadari bahwa kualitas merupakan salah satu faktor agar produk mampu memenuhi permintaan pasar. Salah satu produk yang dihasilkan PT. XYZ adalah closet tipe CW420J. Produk tersebut sering kali tidak dapat memenuhi permintaan pasar, dan salah satu hal yang disorot pihak manajemen PT. XYZ sebagai penyebab adalah terkait kualitas produknya. Maka tujuan penelitian ini adalah melakukan analisis terhadap pengendalian kualitas produk closet tipe $C W 420 \mathrm{~J}$ tersebut. Metode yang digunakan pada penelitian ini adalah Peta Kendali p. Hasil pengolahan dengan menggunakan Peta Kendali $p$ menunjukkan bahwa terdapat sebanyak $47 \%$ dari 30 periode data cacat yang berhasil dikumpulkan menunjukkan adanya proporsi cacat yang berada di luar garis batas kendali. Hal ini membutuhkan tindakan segera dari pihak managemen PT. XYZ untuk melakukan identifikasi lebih lanjut mengenai penyebab terjadinya proses yang di luar kendali tersebut, dan melakukan perbaikan.
\end{abstract}

Kata kunci: Kualitas Produk, Sanitary Wares, Permintaan Pasar, Peta Kendali, Cacat Produk.

\section{Pendahuluan}

Persaingan pasar merupakan hal yang tidak bisa dihindari oleh suatu industri. Salah satu faktor agar suatu produk dapat memenangkan pasar dan diminati oleh konsumen adalah kualitas. Kualitas didefiniskan sebagai konsistensi perbaikan produk (baik berupa barang ataupun jasa) yang dihasilkan, sehingga dapat memenuhi spesifikasi kebutuhan, guna meningkatkan kepuasan pelanggan [1]. Pada beberapa penelitian terdahulu, didapatkan kesimpulan bahwa kualitas produk berpengaruh signifikan terhadap kepuasan pelanggan dan loyalitas pelanggan [2], [3], [4]. Kualitas merupakan salah satu faktor pertimbangan konsumen dalam memilih suatu produk [5], [6], [7]. Jika suatu produk yang dihasilkan tidak dapat memenuhi spesifikasi kualitas yang ditentukan, maka suatu industri tidak akan mampu memenuhi permintaan pasar. Oleh karena itu suatu industri hendaknya memperhatikan aspek kualitas produknya, dan mampu mengendalikannya.

Pengendalian kualitas produk merupakan kombinasi alat dan teknik untuk mengendalikan kualitas produk dengan biaya yang seekonomis mungkin, namun tetap memenuhi syarat pemesan [1]. Praktik penerapan pengendalian kualitas produk dimulai dari pengecekan apakah suatu proses produksi produk tersebut masih berada dalam batas pengendali statistik [1]. Alat yang digunakan untuk melakukan langkah awal pengendalian kualitas statistik tersebut adalah Peta Kendali [8].

PT. XYZ adalah perusahaan yang memproduksi Sanitary Wares yang mengutamakan kualitas produk-produk yang dihasilkannya. Produk yang dihasilkan dipasarkan secara lokal maupun ekspor. Salah satu produk yang dihasilkan adalah produk toilet dengan tipe CW420J. Permintaan dari pasar akan produk closet tipe CW420J sering sekali tidak dapat terpenuhi oleh PT. XYZ. Diantara penyebab yang dihipotesiskan adalah banyaknya defect (cacat) dan juga masalah-masalah lain pada saat proses produksi. Oleh karena itu, pada penelitian ini dianalisis mengenai banyaknya cacat produk, apakah masih dalam batas normal atau sudah melewati batas normal tersebut, menggunakan Peta Kendali.

\section{Metode Penelitian}

Penelitian ini dilakukan pada PT. Surya Toto Indonesia, Tbk. Unit Cikupa. Adapun mekanisme penelitian ini adalah sebagai berikut:

1. Melakukan studi literatur

2. $\quad$ Melakukan studi lapangan (pilot study)

3. Menentukan permasalahan yang akan diselesaikan

4. Mengumpulkan data cacat produk menggunakan Check Sheet.

5. Melakukan uji kecukupan data cacat produk

6. Melakukan analisis pengendalian kualitas menggunakan Peta Kendali p

Copyright (C) 2018, Kaizen : Management Systems \& Industrial Engineering Journal ISSN 15222-96806 (print), ISSN $155222-95973$ (online) 


\section{KAIZEN : MANAGEMENT SYSTEMS \& INDUSTRIAL ENGINEERING JOURNAL VOL. 3 NO. 2 TEKNIK INDUSTRI UNIVERSITAS PGRI MADIUN}

\section{Hasil dan Pembahasan}

Pengumpulan data dilakukan di PT. XYZ. Pengumpulan data cacat produk closet tipe CW420J dilakukan menggunakan Check Sheet, pada data produksi 30 bulan ke belakang. Adapun hasil pengumpulan data cacat produk closet tipe CW420J beserta hasil perhitungan proporsi cacatnya dapat dilihat pada Tabel 1. Data mengenai proporsi cacat produk closet tipe CW420J kemudian diuji kecukupannya menggunakan Persamaan 1. Berdasarkan perhitungan kecukupan data menggunakan Persamaan (1), diperoleh $\mathrm{N}^{\prime}=10,36 \approx 11$ data. Maka jumlah data pengamatan yang telah dikumpulkan dapat dinyatakan cukup, karena $\mathrm{N}^{\prime} \leq$ N.

Tabel 1. Data Jumlah Cacat Produk Closet Tipe CW420J

\begin{tabular}{|c|c|c|c|}
\hline Batch & $\begin{array}{c}\text { Jumlah } \\
\text { produksi }\end{array}$ & $\begin{array}{c}\text { Jumlah } \\
\text { cacat }\end{array}$ & $\begin{array}{c}\text { Proporsi } \\
\text { cacat }\end{array}$ \\
\hline 1 & 3264 & 421 & 0,13 \\
\hline 2 & 3012 & 411 & 0,14 \\
\hline 3 & 2869 & 468 & 0,16 \\
\hline 4 & 3305 & 379 & 0,11 \\
\hline 5 & 2963 & 396 & 0,13 \\
\hline 6 & 3471 & 426 & 0,12 \\
\hline 7 & 2986 & 432 & 0,14 \\
\hline 8 & 3197 & 335 & 0,10 \\
\hline 9 & 3063 & 439 & 0,14 \\
\hline 10 & 2987 & 443 & 0,15 \\
\hline 11 & 2862 & 388 & 0,14 \\
\hline 12 & 2137 & 309 & 0,14 \\
\hline 13 & 3359 & 348 & 0,10 \\
\hline 14 & 3232 & 440 & 0,14 \\
\hline 15 & 3190 & 527 & 0,17 \\
\hline
\end{tabular}

\begin{tabular}{|c|c|c|c|}
\hline Batch & $\begin{array}{c}\text { Jumlah } \\
\text { produksi }\end{array}$ & $\begin{array}{c}\text { Jumlah } \\
\text { cacat }\end{array}$ & $\begin{array}{c}\text { Proporsi } \\
\text { cacat }\end{array}$ \\
\hline 16 & 3398 & 560 & 0,16 \\
\hline 17 & 2986 & 355 & 0,12 \\
\hline 18 & 3419 & 483 & 0,14 \\
\hline 19 & 2874 & 512 & 0,18 \\
\hline 20 & 3447 & 578 & 0,17 \\
\hline 21 & 2833 & 315 & 0,11 \\
\hline 22 & 3050 & 321 & 0,11 \\
\hline 23 & 2164 & 320 & 0,15 \\
\hline 24 & 3266 & 405 & 0,12 \\
\hline 25 & 3494 & 425 & 0,12 \\
\hline 26 & 2881 & 319 & 0,11 \\
\hline 27 & 3432 & 320 & 0,09 \\
\hline 28 & 3466 & 535 & 0,15 \\
\hline 29 & 2814 & 425 & 0,15 \\
\hline 30 & 3468 & 563 & 0,16 \\
\hline
\end{tabular}

$N^{s}=\left[\frac{\sqrt{\frac{k}{N} \sqrt{N x^{2}-\left(\sum x\right)^{2}}}}{\sum x}\right]^{2}$

Keterangan:

$N^{\prime} \quad$ : jumlah minimum data yang seharusnya diambil

$N \quad$ : jumlah data yang telah diambil, dalam hal ini $\mathrm{N}=30$

$k \quad$ : tingkat keyakian, dalam hal ini diambil confidence level $=95 \%$, sehingga $\mathrm{k}=2$

$s \quad$ : derajat ketelitian, dalam hal ini diambil $10 \%$, sehingga $\mathrm{s}=0,1$

$X \quad$ : data pengamatan

Pembuatan body produk closet tipe CW42J, terdapat beberapa hal yang perlu diperhatikan dalam rangka pengendalian kualitas produk. Pertama adalah sirkulasi slip (bahan baku), pengecekan atau pemeriksaan sirkulasi slip sebelum proses produksi harus dilakukan agar tidak terjadi hambatan pada saat pengisian slip ke cetakan. Kedua adalah cetakan, agar saat proses pencetakan (forming) berjalan lancar (cetakan bersih dan tidak lengket saat digunakan), cetakan harus diatur suhunya dari sore sampai dengan pagi hari. Ketiga adalah pemeriksaan body hasil cetakan. Jika tidak ada cacat, maka akan dilanjutkan ke proses berikutnya. Jika ada kecacatan, maka dicek kembali apakah bisa diperbaiki atau tidak. Jika bisa diperbaiki, maka body hasil cetakan diolah kembali. Sebelum memasuki proses assembly, dilakukan pengecekan kembali pada body tersebut. Diantara jenis cacat yang terdapat pada produk closet tipe CW420J adalah sebagai berikut :

$\begin{array}{llll}\mathrm{D} & \text { : ukuran di luar standar } & \mathrm{L} & \text { : bocor } \\ \mathrm{F} & \text { : berlubang } & \mathrm{K} & \text { : retak } \\ \mathrm{G} & \text { : cat mengelupas } & \mathrm{V} & \text { : debu body } \\ \mathrm{E} & \text { : retak air panas } & \mathrm{H} & \text { : cat kurang }\end{array}$

$\mathrm{Z} \quad$ : lain-lain (cacat selain yang telah disebutkan)

Selain melakukan pengendalian terhadap proses yang berhubungan langsung dengan pembuatan produk, pengendalian juga dilakukan terhadap lingkungan produksi, demi terjaganya kualitas produk. Diantaranya yakni menjaga kebersihan alat dan tempat kerja agar pekerja nyaman dalam melakukan pekerjaannya. Suhu ruangan juga juga dijaga agar selalu stabil. Pengarahan kepada pekerja juga dilakukan, agar pekerja berhati-hati dalam pekerjaannya, fokus pada apa yang dilakukan, dan semangat dalam bekerja. Berdasarkan penjelasan sebelumnya, produk closet tipe CW420J memiliki jenis cacat atribut, dan sebagaimana 


\section{KAIZEN : MANAGEMENT SYSTEMS \& INDUSTRIAL ENGINEERING JOURNAL VOL. 3 NO. 2 TEKNIK INDUSTRI UNIVERSITAS PGRI MADIUN}

dilihat pada Tabel 1, bahwa ukuran sampel tidak konstan, maka peta kendali yang dapat digunakan adalah Peta Kendali p.

Berikut ini adalah langkah-langkah pembuatan Peta Kendali p anatar lain :

1. Kumpulkan data kecacatan produk.

2. Hitung nilai proporsi cacat (p) untuk setiap batch (pengamatan, i), menggunakan Persamaan (2).

$$
p_{i}=\frac{x_{i}}{n_{i}}
$$

3. Hitung nilai rata-rata proporsi cacat, sebagai center line (CL), menggunakan Persamaan (3).

$$
\bar{p}=\frac{\sum x}{\sum n}
$$

4. Hitung upper center line (UCL), menggunakan Persamaan (4).

$$
U C L_{i}=\bar{p}+3 \sqrt{\frac{p_{i}(-p)}{n_{i}}}
$$

5. Hitung lower center line (LCL), menggunakan Persamaan (5).

$$
L C L_{i}=\bar{p}-3 \sqrt{\frac{p_{1-p)}}{n_{i}}}
$$

6. Gambarkan Peta Kendali p.

Berdasarkan perhitungan proporsi cacat, CL, UCL, dan LCL sebagaimana pada Persamaan (2), (3), (4), dan (5), maka didapatkan hasil sebagaimana ditampilkan pada Tabel 2. Hasil perhitungan jumlah produk cacat sebagaimana ditampilkan pada Tabel 2 kemudian divisualisasikan dalam Peta Kendali p, yakni pada Gambar 1. Berdasarkan Gambar 1 dapat dilihat bahwa terdapat beberapa data proporsi cacat yang berada di luar batas kendali, yakni proporsi cacat pada periode produksi 3, 4, 8, 13, 15, 16, 19, 20, 21, 22, 26, 27, 28, dan 30. Dengan demikian, secara keseluruhan terdapat 14 dari 30 data proporsi cacat yang berada di luar batas kendali $(47 \%)$.

Sebagaimana dapat dilihat pada Gambar 1, bahwa suatu peta kendali memiliki 3 garis utama, yakni garis tengah (center line, CL), garis batas pengendali atas (upper center line, UCL), dan garis batas pengendali bawah (lower center line, LCL). Titiktitik proporsi cacat yang berada pada sekitar garis tengah (CL) menggambarkan cacat produk yang disebabkan oleh proses yang wajar (normal). Hal ini tidak memerlukan tindakan lanjutan dari pihak manajemen produksi. Titik-titik tersebut memang tidak selalu stabil (tidak selalu berada dalam garis lurus) dikarenakan jalannya sistem dipengaruhi oleh hal-hal yang probabilistik, namun masih terkendali (berada dalam batas antara UCL sampai dengan LCL). Namun titik-titik proporsi cacat yang berada di luar garis batas pengendali, baik atas maupun bawah, dapat diinterpretasikan sebagai bukti bahwa proses produksi berjalan tidak terkendali (indikasi adanya penyebab khusus). Oleh karena itu, diperlukan tindakan penyelidikan lanjutan mengenai penyebab cacat pada periode-periode produksi tersebut (periode produksi 3, 4, 8, 13, 15, 16, 19, 20, 21, 22, 26, 27, 28, dan 30), dan perbaikan untuk dapat meningkatkan performa sistem.

Tabel 2. Hasil Perhitungan CL, UCL, dan LCL untuk Peta Kendali p

\begin{tabular}{|c|c|c|c|c|c|c|}
\hline Batch & Jumlah Produksi & Jumlah Cacat & Proporsi Cacat & CL & UCL & LCL \\
\hline 1 & 3264 & 421 & 0,13 & 0,136 & 0,154 & 0,118 \\
\hline 2 & 3012 & 411 & 0,14 & 0,136 & 0,154 & 0,117 \\
\hline 3 & 2869 & 468 & 0,16 & 0,136 & 0,155 & 0,116 \\
\hline 4 & 3305 & 379 & 0,11 & 0,136 & 0,153 & 0,118 \\
\hline 5 & 2963 & 396 & 0,13 & 0,136 & 0,154 & 0,117 \\
\hline 6 & 3471 & 426 & 0,12 & 0,136 & 0,153 & 0,118 \\
\hline 7 & 2986 & 432 & 0,14 & 0,136 & 0,154 & 0,117 \\
\hline 8 & 3197 & 335 & 0,10 & 0,136 & 0,154 & 0,117 \\
\hline 9 & 3063 & 439 & 0,14 & 0,136 & 0,154 & 0,117 \\
\hline 10 & 2987 & 443 & 0,15 & 0,136 & 0,154 & 0,117 \\
\hline 11 & 2862 & 388 & 0,14 & 0,136 & 0,155 & 0,116 \\
\hline 12 & 2137 & 309 & 0,14 & 0,136 & 0,158 & 0,113 \\
\hline 13 & 3359 & 348 & 0,10 & 0,136 & 0,153 & 0,118 \\
\hline 14 & 3232 & 440 & 0,14 & 0,136 & 0,154 & 0,118 \\
\hline 15 & 3190 & 527 & 0,17 & 0,136 & 0,154 & 0,117 \\
\hline 16 & 3398 & 560 & 0,16 & 0,136 & 0,153 & 0,118 \\
\hline 17 & 2986 & 355 & 0,12 & 0,136 & 0,154 & 0,117 \\
\hline 18 & 3419 & 483 & 0,14 & 0,136 & 0,153 & 0,118 \\
\hline 19 & 2874 & 512 & 0,18 & 0,136 & 0,155 & 0,116 \\
\hline 20 & 3447 & 578 & 0,17 & 0,136 & 0,153 & 0,118 \\
\hline
\end{tabular}

Copyright (C) 2018, Kaizen : Management Systems \& Industrial Engineering Journal ISSN 15222-96806 (print), ISSN 155222-95973 (online) 
KAIZEN : MANAGEMENT SYSTEMS \& INDUSTRIAL ENGINEERING JOURNAL VOL. 3 NO. 2 TEKNIK INDUSTRI UNIVERSITAS PGRI MADIUN

Tabel 2. Hasil Perhitungan CL, UCL, dan LCL untuk Peta Kendali p (Lanjutan)

\begin{tabular}{|c|c|c|c|c|c|c|}
\hline Batch & Jumlah Produksi & Jumlah Cacat & Proporsi Cacat & CL & UCL & LCL \\
\hline 21 & 2833 & 315 & 0,11 & 0,136 & 0,155 & 0,116 \\
\hline 22 & 3050 & 321 & 0,11 & 0,136 & 0,154 & 0,117 \\
\hline 23 & 2164 & 320 & 0,15 & 0,136 & 0,158 & 0,114 \\
\hline 24 & 3266 & 405 & 0,12 & 0,136 & 0,154 & 0,118 \\
\hline 25 & 3494 & 425 & 0,12 & 0,136 & 0,153 & 0,118 \\
\hline 26 & 2881 & 319 & 0,11 & 0,136 & 0,155 & 0,116 \\
\hline 27 & 3432 & 320 & 0,09 & 0,136 & 0,153 & 0,118 \\
\hline 28 & 3466 & 535 & 0,15 & 0,136 & 0,153 & 0,118 \\
\hline 29 & 2814 & 425 & 0,15 & 0,136 & 0,155 & 0,116 \\
\hline 30 & 3468 & 563 & 0,16 & 0,136 & 0,153 & 0,118 \\
\hline Jumlah & 92889 & 12598 & & & & \\
\hline
\end{tabular}

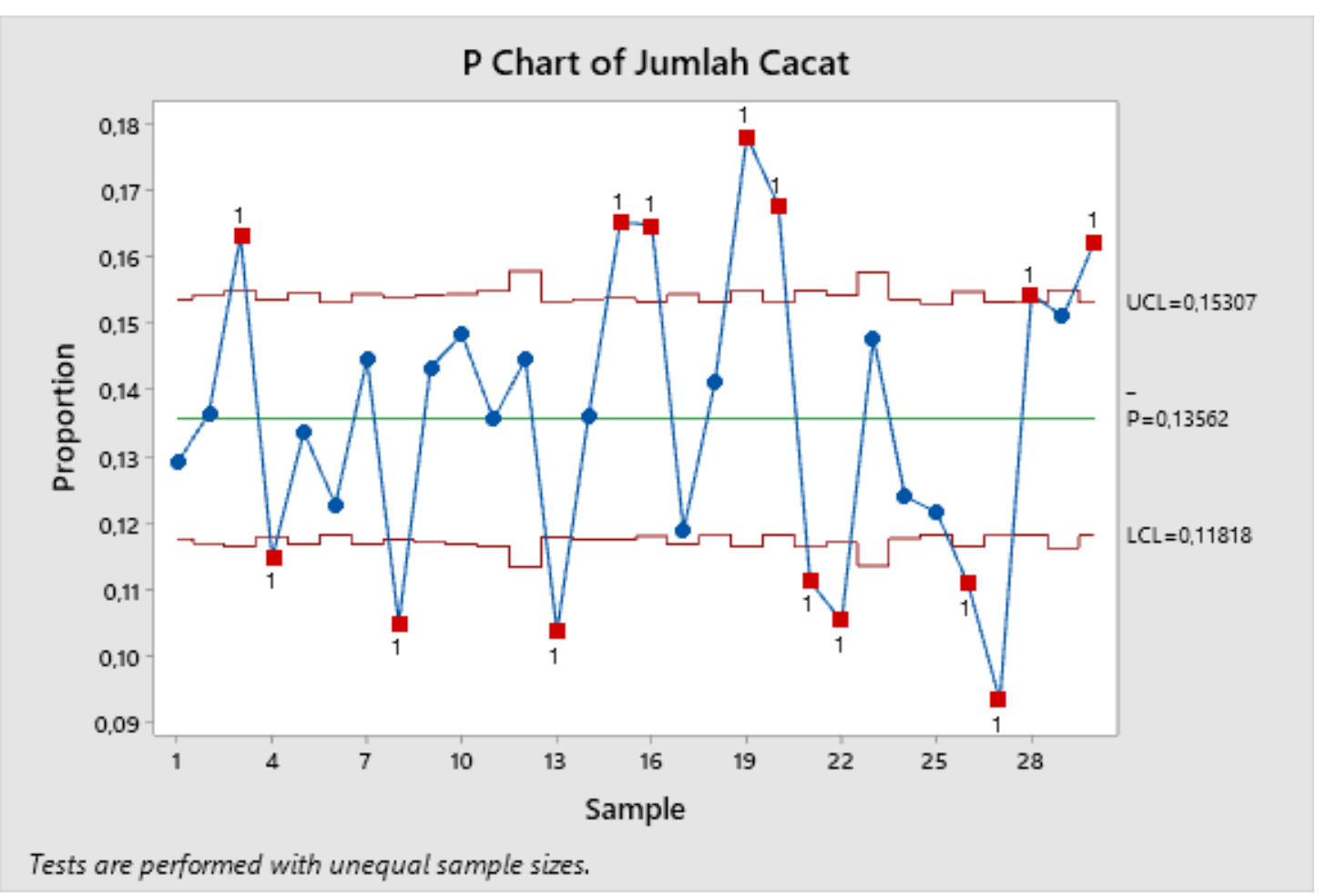

Gambar 1. Peta Kendali p

\section{Simpulan}

Dari hasil analisis pengendalian kualitas produk closet tipe CW420J menggunakan Peta Kendali p, dapat disimpulkan bahwa terdapat $45 \%$ dari 30 data proporsi cacat yang berada di luar batas kendali. Hal ini mengindikasikan adanya suatu penyebab khusus, yang menyebabkan proses produksi produk closet tipe CW420J berjalan tidak terkendali. Hal ini memerlukan tindakan lanjutan dari pihak manajemen PT. XYZ untuk segera menyelidiki penyebab tersebut, guna dapat diminimalisir, dan pada akhirnya mampu meningkatkan performa sistem. Saran untuk penelitian selanjutnya adalah meneliti mengenai hubungan antara frekuensi tidak terpenuhinya permintaan pasar akan produk closet tipe CW420J dengan tingkat cacat produk tersebut. Hal ini adalah untuk memastikan apakah tingkat cacat yang masih banyak (47\%) berada di luar batas kendali tersebut benar-benar menyebabkan tidak terpenuhinya permintaan pasar. 


\section{Daftar Pustaka}

[1] Irwan and D. Haryono, Pengendalian Kualitas Statistik. Bandung: Alfabeta, 2015.

[2] A. Afnina and Y. Hastuti, "Pengaruh Kualitas Produk terhadap Kepuasan Pelanggan," J. Samudra Ekon. dan Bisnis, vol. 9, no. 1, pp. 21-30, 2018.

[3] D. Anggraeni, S. Kumadji, and S. Sunarti, "Pengaruh Kualitas Produk Terhadap Kepuasan dan Loyalitas Pelanggan ( Survei pada Pelanggan Nasi Rawon di Rumah Makan Sakinah Kota Pasuruan)," J. Adm. Bisnis S1 Univ. Brawijaya, vol. 37, no. 1, pp. 171-177, 2016.

[4] Y. H. Hayati and G. Sekartaji, "Pengaruh Kualitas Produk Terhadap Kepuasan Konsumen Di Restoran Bebek Dan Ayam Goreng Pak Ndut Solo," JIMFE (Jurnal Ilm. Manaj. Fak. Ekon., vol. 1, no. 1, pp. 49-56, 2015.

[5] F. G. Igir, J. R. E. Tampi, and H. Taroreh, "Pengaruh Kualitas Produk dan Harga terhadap Keputusan Pembelian Mobil Daihatsu Grand Max Pick Up," J. Adm. Bisnis, vol. 6, no. 2, pp. 86-96, 2018.

[6] S. Istoto and I. K. Subagja, "Pengaruh Kualitas Produk Dan Promosi Terhadap Keputusan Pembelian Buah Melon PT. Syafina Niaga," J. Manaj. Bisnis Krisnadwipayana, vol. 6, no. 2, 2018.

[7] Riyono and G. E. Budiharja, "Pengaruh Kualitas, Harga, Promosi dan Brand Image Terhadap Keputusan Pembelian Produk Aqua di Kota Pati,” J. Stie Semarang, vol. 8, no. 2, pp. 92-121, 2016.

[8] H. Tannady, Pengendalian Kualitas. Yogyakarta: Graha Ilmu, 2015. 